\title{
Hypertriglyceridemic-waist phenotype and glucose intolerance among Canadian Inuit: the International Polar Year Inuit Health Survey for Adults 2007-2008
}

\author{
Grace M. Egeland PhD, Zhirong Cao MSc, T. Kue Young MD PhD
}

\begin{abstract}
- Abstract
Background: Inuit have not experienced an epidemic in type 2 diabetes mellitus, and it has been speculated that they may be protected from obesity's metabolic consequences. We conducted a population-based screening for diabetes among Inuit in the Canadian Arctic and evaluated the association of visceral adiposity with diabetes.
\end{abstract}

Methods: A total of 36 communities participated in the International Polar Year Inuit Health Survey. Of the 2796 Inuit households approached, 1901 (68\%) participated, with 2595 participants. Households were randomly selected, and adult residents were invited to participate. Assessments included anthropometry and fasting plasma lipids and glucose, and, because of survey logistics, only $32 \%$ of participants underwent a $75 \mathrm{~g}$ oral glucose tolerance test. We calculated weighted prevalence estimates of metabolic risk factors for all participants.
Results: Participants' mean age was 43.3 years; $35 \%$ were obese, $43.8 \%$ had an at-risk waist, and $25 \%$ had an elevated triglyceride level. Diabetes was identified in $12.2 \%$ of participants aged 50 years and older and in $1.9 \%$ of those younger than 50 years. A hypertriglyceridemicwaist phenotype was a strong predictor of diabetes (odds ratio [OR] 8.6, 95\% confidence interval [CI] 2.1-34.6) in analyses adjusted for age, sex, region, family history of diabetes, education and use of lipid-lowering medications.

Interpretation: Metabolic risk factors were prevalent among Inuit. Our results suggest that Inuit are not protected from the metabolic consequences of obesity, and that their rate of diabetes prevalence is now comparable to that observed in the general Canadian population. Assessment of waist circumference and fasting triglyceride levels could represent an efficient means for identifying Inuit at high risk for diabetes.
I ndigenous people across the Arctic continue to undergo cultural transitions that affect all dimensions of life, with implications for emerging obesity and changes in patterns of disease burden. ${ }^{1-3}$ A high prevalence of obesity among Canadian Inuit has been noted, ${ }^{3,4}$ and yet studies have suggested that the metabolic consequences of obesity may not be as severe among Inuit as they are in predominantly Caucasian or First Nations populations. ${ }^{4}$ ${ }^{6}$ Conversely, the prevalence of type 2 diabetes mellitus, which was noted to be rare among Inuit in early studies, ${ }^{7.8}$ now matches or exceeds that of predominately Caucasian comparison populations in Alaska and Greenland. ${ }^{9-11}$ However, in Canada, available reports suggest that diabetes prevalence among Inuit remains below that of the general Canadian population., ${ }^{3,12}$

Given the rapid changes in the Arctic and a lack of comprehensive and uniform screening assessments, we used the International Polar Year Inuit
Health Survey for Adults 2007-2008 to assess the current prevalence of glycemia and the toll of age and adiposity on glycemia in this population. However, adiposity is heterogeneous, and simple measures of body mass index (BMI) in $\mathrm{kg} / \mathrm{m}^{2}$ and waist circumference do not measure visceral adiposity (or intra-abdominal adipose tissue), which is considered more deleterious than subcutaneous fat. ${ }^{13}$ Therefore, we evaluated the "hypertriglyceridemicwaist" phenotype (i.e., the presence of both an atrisk waist circumference and an elevated triglyceride level) as a proxy indicator of visceral fat. ${ }^{13-15}$

\section{Methods}

\section{Design and participants}

The cross-sectional International Polar Year Inuit Health Survey for Adults 2007-2008 was conducted in the summer and fall of 2007 and 2008 by the Canadian Coastguard Ship Amundsen in 33 coastal communities and by land-teams
Competing interests:

None declared.

This article has been peer reviewed.

Correspondence to:

Dr. Grace M. Egeland, grace.egeland@mcgill.ca

CMAJ 2011. DOI:10.1503 /cmaj.101801 
in 3 noncoastal communities. All communities in Inuvialuit Settlement Region, Northwest Territories, in Nunavut and in Nunatsiavut, Northern Labrador, were included (Appendix 1, available at www.cmaj.ca/cgi/content/full/cmaj.101801 /DC1).

The survey randomly selected households from each community and recruited people from within each household by inviting adults aged 18 years or older to participate. A total of 2796 Inuit households were approached, and 1901 households (68\%) participated, with a total of 2595 participants. The median number of participants per community was 54 participants (25th percentile $=42,75$ th percentile $=102$ ).

The survey was developed through participatory processes ${ }^{16}$ (www.inuithealthsurvey.ca). An ethics certificate from the McGill University Faculty of Medicine Institutional Review Board and territorial research licenses were obtained.

\section{Assessments}

Trained interviewers who were bilingual in English and Inuit dialects administered questionnaires to collect data on household composition, diet, use of alcohol and tobacco, physical activity, and mental health and well-being. Nurses obtained medical histories and information on current medication use, took anthropometric measures, collected fasting venous blood samples from participants and administered a twohour $75 \mathrm{~g}$ oral glucose tolerance test to a subgroup of participants.

Study participants who received the oral glucose tolerance test $(n=831$ [32\%]) comprised those who, owing to survey logistics, were examined in the morning. Those who reported taking medication for diabetes or who had an elevated fasting capillary glucose level $(>7.0 \mathrm{mmol} / \mathrm{L})$ were excluded from this test. Nurses conducted early morning home visits to collect fasting blood samples from participants scheduled later in the day. Fasting and two-hour glucose levels were assessed using the glucose hexokinase II method. ${ }^{17}$ Fasting serum total cholesterol, highdensity lipoprotein (HDL) cholesterol and triglycerides were determined using enzymatic colorimetric tests. ${ }^{18}$ All laboratory tests were conducted by Nutrasource Diagnostics, Guelph, Ont. (Life Laboratories-Gamma Dynacare).

A BMI of $25.0-29.9 \mathrm{~kg} / \mathrm{m}^{2}$ was considered overweight, and a BMI of $30 \mathrm{~kg} / \mathrm{m}^{2}$ or greater was considered obese. An at-risk waist was defined as $88 \mathrm{~cm}$ or greater for women and $102 \mathrm{~cm}$ or greater for men. ${ }^{19}$ Low-density lipoprotein (LDL) cholesterol was calculated. ${ }^{20}$ The mean fasting period was 11.2 (standard deviation [SD] 2.4) hours. Fasting glycemia was evaluated according to severity, with threshold levels of $\geq 5.6, \geq 6.0$ and $\geq 7.0 \mathrm{mmol} / \mathrm{L}$. Prediabetes was defined as a fasting glucose level of $5.6-6.9 \mathrm{mmol} / \mathrm{L}$ on oral glucose tolerance test or a two-hour oral glucose tolerance test of 7.8$11.0 \mathrm{mmol} / \mathrm{L} .{ }^{21}$ Diabetes was defined as a fasting glucose level of $7.0 \mathrm{mmol} / \mathrm{L}$ or greater, a twohour oral glucose tolerance of $11.0 \mathrm{mmol} / \mathrm{L}$ or greater, or taking medication for diabetes. ${ }^{22} \mathrm{An}$ elevated triglyceride level was defined as a serum triglyceride level of $1.7 \mathrm{mmol} / \mathrm{L}$ or greater. An at-risk cholesterol level was defined as either an LDL cholesterol level of $5 \mathrm{mmol} / \mathrm{L}$ or greater or a ratio of total cholesterol to HDL cholesterol of $6.0 \mathrm{mmol} / \mathrm{L}$ or greater.

\section{Statistical analysis}

The prevalence of risk factors for chronic diseases was evaluated by region, sex and age (younger than v. $\geq 50$ years) using $\chi^{2}$ tests. The association of the hypertriglyceridemic-waist phenotype with fasting glycemia and diabetes was evaluated using logistic regression adjusted for age, sex, current smoking behaviour, education level, region, family history of diabetes and current use of lipid-lowering medications. Because of the likelihood of strong alcoholrelated effects on expression of the phenotype and glycemia, all analyses were reconducted after removal of data for participants who reported having consumed alcohol during the past year $(n=678)$. These results are presented in Appendix 2 (available at www.cmaj.ca/cgi /content/full/cmaj.101801/DC).

The prevalence results were weighted to the general population of Inuit in the three jurisdictions of the survey. Odds ratios (ORs) and 95\% confidence intervals (CIs) were estimated using unadjusted and adjusted regression analyses, evaluating outcomes of fasting glycemia and type 2 diabetes. Further, all analyses were corrected for multiple people per household using a cluster statement. Weight 1 was calculated based on the total number of households in the community and the number of households sampled in that community. Weight 2 was calculated based on the total number of people in the household and the number of people sampled within that house. Poststratification survey weight 3 was used to correct the difference in sex distribution between our sample and its population distribution. The final weight of each person was calculated multiplying the three weights noted above.

\section{Results}

The weighted average age of study participants was 43.3 years, and $61.5 \%$ of participants were 
women. Weighted prevalence rates indicated that $28 \%$ of Inuit in the regions surveyed were overweight, whereas $35.0 \%$ were obese and $43.8 \%$ had an at-risk waist (Table 1). Smoking was highly prevalent, with $68.8 \%$ of the population smoking, and $29.2 \%$ smoking more than 10 cigarettes per day (Table 1). Past-year alcohol consumption was reported by $71.6 \%$ of participants younger than 50 years and $38.9 \%$ of those 50 years and older. Elevated triglycerides were identified in $25 \%$, whereas at-risk cholesterol was identified in $8.2 \%$.

The prevalence of the hypertriglyceridemicwaist phenotype varied markedly by region. In Inuvialuit Settlement Region, it was 35.2\% (weighted; $n=244,95 \%$ CI 27.1-42.7), which was significantly higher than in Nunatsiavut and Nunavut. In Nunatsiavut, it was $23.8 \%$ (weighted; $n=255,95 \%$ CI 17.8-29.8), which was significantly higher than in Nunavut, where it was $13.5 \%$ (weighted; $n=1439,95 \%$ CI 11.0-15.8) (data not shown; $\chi^{2}, p \leq 0.05$ ). Similarly, the prevalence of glycemia (plasma glucose $\geq 6.0 \mathrm{mmol} / \mathrm{L}$ ) was higher among participants in Inuvialuit Settlement Region (13.9\%) compared with Nunatsiavut $(3.7 \%)$ and Nunavut $(6.9 \%)\left(\chi^{2}, p \leq 0.05\right)$. However, the prevalence of diabetes was similar across regions, with an overall prevalence of $5.1 \%$. While women had a nearly twofold higher prevalence of at-risk waist relative to men, there were no sex differences in the prevalence of the hypertriglyceridemic-waist phenotype. Those 50 years of age or older had a greater prevalence of obesity, an at-risk waist and a hypertriglyceridemic-waist phenotype, but a lower prevalence of smoking and alcohol consumption relative to those less than 50 years of age (Table 1).

Striking age differences were noted in glycemia prevalence, with $31.5 \%$ of participants 50 years of age and older having a fasting plasma glucose of $\geq 5.6 \mathrm{mmol} / \mathrm{L}$, in contrast to $8.6 \%$ among those younger than 50 years (Table 2). Diabetes was identified in $12.2 \%$ of those aged 50 years or older, in contrast to $1.9 \%$ of those younger than 50 years. However, no significant differences in glycemia between men and women were identified (Table 2). There was an increased gradient in risk for glycemia $(\geq 5.6 \mathrm{mmol} / \mathrm{L})$ by the presence of an at-risk waist or elevated fasting triglyceride level, with the highest proportion of participants with glycemia observed among those with both risk factors who were 50 years of age or older (Figure 1).

In weighted multivariable analyses, adjusting for age, sex, region, education, family history of diabetes and use of lipid-lowering medications, the hypertriglyceridemic-waist phenotype was

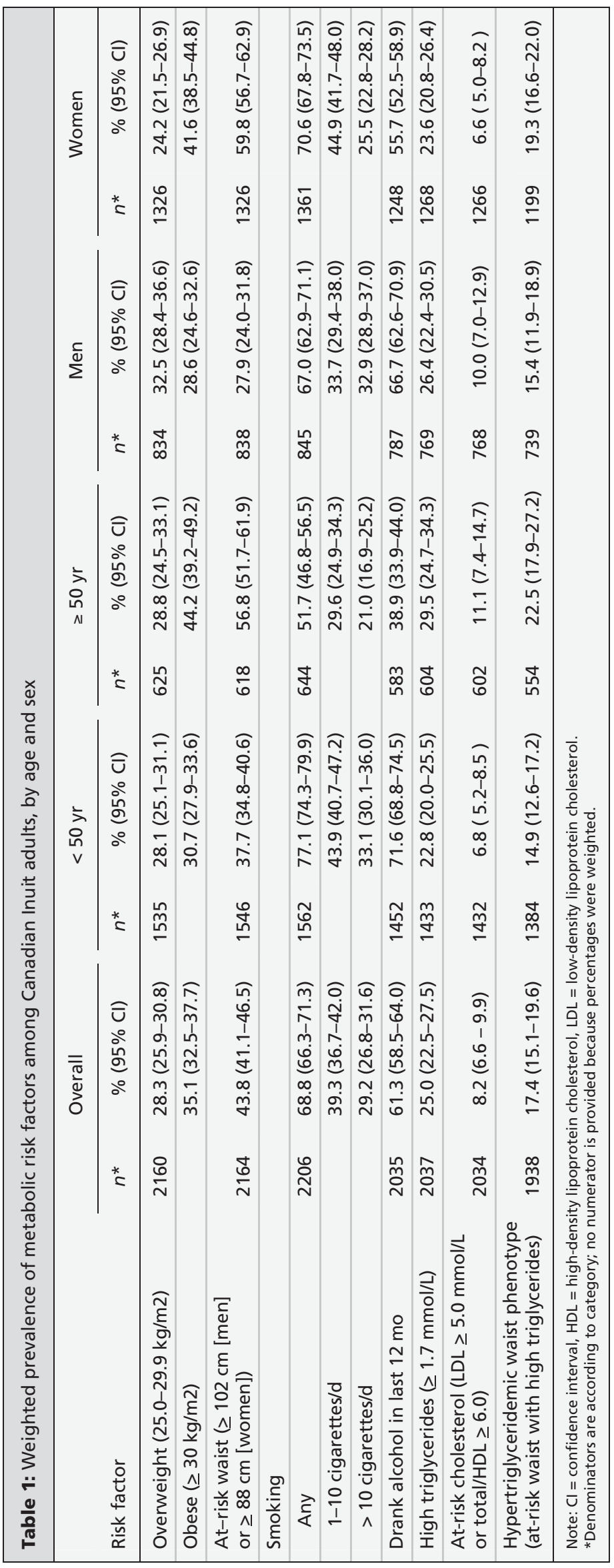




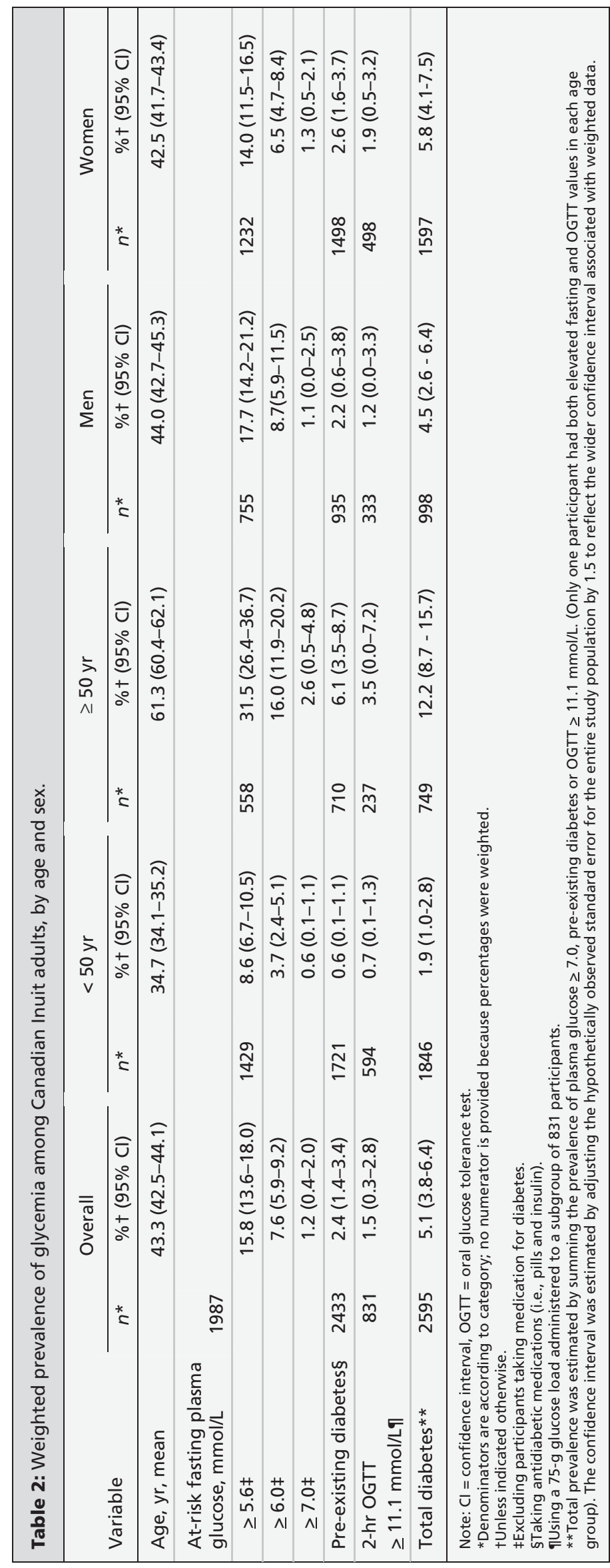

significantly and strongly associated with an elevated fasting glucose (OR 4.3, 95\% CI 2.4-7.5), whereas an at-risk waist alone was moderately associated with an elevated fasting glucose (OR 2.2, 95\% CI 1.3-3.9) (Table 3).

In a similar multivariable model, the hypertriglyceridemic-waist phenotype was significantly and strongly associated with diabetes (OR 8.6, 95\% CI 2.1-34.6), whereas an at-risk waist alone did not show a significant association with diabetes (OR 3.7, 95\% CI 0.8-16.8) (Table 3). There were no significant age-by-phenotype interactions noted in the multivariable logistic regression models, and additional adjustment for fasting duration did not alter the results. In analyses excluding all participants who reported drinking alcohol in the past year, significant associations between the hypertriglyceridemicwaist phenotype and risk for diabetes persisted, albeit the magnitude of the association was attenuated (Appendix 2, available at www.cmaj.ca /cgi/content/full/cmaj.101801/DC).

\section{Interpretation}

We found that, among Inuit, the hypertriglyceridemic-waist phenotype is related to risk of fasting glycemia and type 2 diabetes, and that the rates of diabetes in this population are now comparable to those observed among the general Canadian population. ${ }^{24}$

Our study identified a prevalence of diabetes of $1.9 \%$ among Inuit younger than age 50 (mean age 34.3 years), which is comparable to the general Canadian age-specific prevalence of $2.4 \%$ among 35-39-year-olds reported by the National Diabetes Surveillance System based on administrative data. ${ }^{24}$ It should be noted that the prevalence reported by the National Diabetes Surveillance System is probably underestimated because it is based on diagnoses of diabetes rather than on oral glucose tolerance testing or fasting glucose surveys. Similarly, a prevalence of diabetes of $12.2 \%$ was identified among Inuit aged 50 years or older (mean age 61.2 years), which is comparable to the age-specific prevalence in the general Canadian population of $15.7 \%$ among those aged $60-64$ years. ${ }^{24}$

Our study adds to the limited information available on the prevalence of diabetes in Inuit. The existing literature is limited to a 2006 survey based on self-reported data that showed a $3 \%$ prevalence among adults aged 15 and older ${ }^{12}$ and a 2004 survey of adults in Nunavik, Quebec, that showed a prevalence of $4.7 \%$ based on fasting glucose screening and medical chart reviews. ${ }^{3}$ Our findings suggest that the prevalence of diabetes among Canadian Inuit is higher than previ- 
ously recognized, but remains lower than that observed among First Nations people. ${ }^{25}$

Further, our data corroborate the limited number of studies that suggest that the hypertriglyceridemic-waist phenotype is more closely related to diabetes than to waist circumference alone. ${ }^{13-15}$ While Inuit women had a higher degree of obesity and central fat patterning than men, there were no sex differences noted in the prevalence of the hypertriglyceridemic waist or in the risk for glycemia. Similarly, in a large, populationbased US survey, no sex difference was noted in the prevalence of the phenotype. ${ }^{26}$ In the Quebec Health Survey, using slightly different cut-offs, $19 \%$ of men aged 18-74 years had the phenotype (waist girth $\geq 90 \mathrm{~cm}$ and triglyceride level $\geq 2 \mathrm{mmol} / \mathrm{L}),{ }^{15}$ which is similar to the upper $95 \%$ CI for the prevalence for Inuit men $(18.7 \%)$ observed in this study. Among Quebec men, the phenotype was associated with an OR of 12 for diabetes, which was similar to the unadjusted OR of 15.6 observed for Inuit with the phenotype.

As the proportion of participants who reported having consumed alcohol during the past year was similar across regions, we can only speculate on the reasons for the regional differences observed in the prevalence of the phenotype. Factors associated with acculturation (traditional food, sugar-sweetened beverage consumption, physical activity) may influence triglyceride levels or adiposity and may contribute to the variations observed in the prevalence of the phenotype across the Arctic. These factors are now being evaluated using the data collected for this study.

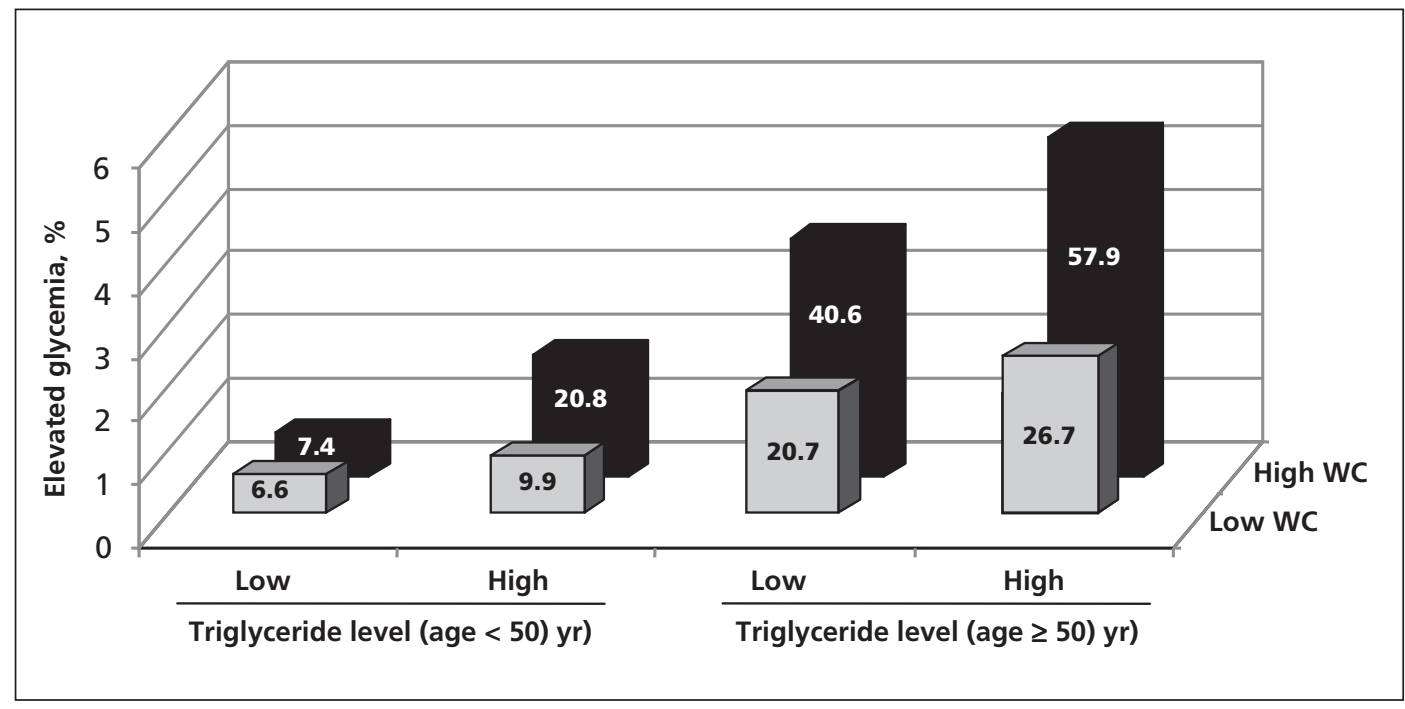

Figure 1: Prevalence of glycemia by age group, waist circumference and fasting serum triglyceride level. Glycemia was defined as a fasting glucose level $\geq 5.6 \mathrm{mmol} / \mathrm{L}$ or taking medication for diabetes. An at-risk waist was defined as $\geq 102 \mathrm{~cm}$ for men or $\geq 88 \mathrm{~cm}$ for women. A high triglyceride level was defined as $\geq 1.7 \mathrm{mmol} / \mathrm{L}$. Note: WC = waist circumference.

Table 3: Weighted estimated odds ratios for fasting glycemia $\geq 5.6 \mathrm{mmol} / \mathrm{L}^{*}$ and type 2 diabetes $t$ among Canadian Inuit adults, by hypertriglyceridemic-waist phenotype

\begin{tabular}{|c|c|c|c|c|c|c|c|c|}
\hline $\begin{array}{l}\text { Waist circumference } \neq \\
\text { /triglycerides, } \mathrm{mmol} / \mathrm{L}\end{array}$ & $\begin{array}{c}\text { No } \\
n=1625\end{array}$ & $\begin{array}{c}\text { Yes } \\
n=302\end{array}$ & $\begin{array}{l}\text { Unadjusted } \\
\text { OR }(95 \% \mathrm{Cl})\end{array}$ & $\begin{array}{c}\text { Adjusted } ¥ \\
\text { OR }(95 \% \mathrm{Cl})\end{array}$ & $\begin{array}{c}\text { No } \\
n=1863\end{array}$ & $\begin{array}{c}\text { Yes } \\
n=75\end{array}$ & $\begin{array}{l}\text { Unadjusted } \\
\text { OR }(95 \% \mathrm{Cl})\end{array}$ & $\begin{array}{c}\text { Adjusted§ } \\
\text { OR }(95 \% \mathrm{Cl})\end{array}$ \\
\hline Low WC/< 1.7 & 803 & 65 & 1.0 & 1.0 & 866 & 7 & 1.0 & 1.0 \\
\hline Low WC $/ \geq 1.7$ & 113 & 21 & $1.6(0.8-3.1)$ & $1.0(0.5-2.4)$ & 132 & 3 & $1.1(0.2-5.4)$ & $0.7(0.1-4.8)$ \\
\hline \multicolumn{9}{|c|}{$\begin{array}{l}\text { Note: } \mathrm{OR}=\text { odds ratio, } \mathrm{WC}=\text { waist circumference. } \\
\text { *Or taking medication for diabetes. } \\
\text { tDefined as fasting glucose } \geq 7.0 \mathrm{mmol} / \mathrm{L} \text { or } 2 \text {-hr } 75 \text {-g oral glucose tolerance test } \geq 11.1 \mathrm{mmol} / \mathrm{L} \text { or taking medication for diabetes. } \\
\text { fLow WC was defined as }<102 \mathrm{~cm} \text { (men) or }<88 \mathrm{~cm} \text { (women), and high WC was defined as } \geq 102 \mathrm{~cm} \text { (men) or } \geq 88 \mathrm{~cm} \text { (women). } \\
\text { \$Adjusted for sex, age (in } 5 \text {-yr increments), region, education, family history of diabetes and use of lipid-lowering medication. }\end{array}$} \\
\hline
\end{tabular}




\section{Limitations}

Our study's limitations included its crosssectional design and the preclusion by survey logistics of administering an oral glucose tolerance test to all study participants. Thus, the true overall diabetes prevalence may differ from that ascertained by our study.

\section{Conclusion}

The metabolic syndrome has been proposed as a screening tool to help physicians identify patients with a cluster of abnormalities indicative of increased risk for morbidity and mortality associated with high-risk abdominal obesity. ${ }^{17}$ However, assembling information on the various criteria can be time-consuming. Our study corroborates emerging evidence suggesting that a simple construct may suffice in identifying people at risk for obesity-related complications. ${ }^{13-15,26-}$ ${ }^{28}$ Further, our findings suggest that Inuit ethnicity does not protect obese people from development of diabetes.

\section{References}

1. Bjerregaard P, Young TK, Dewailly E, et al. Indigenous health in the Arctic: an overview of the Circumpolar Inuit population. Scand J Public Health 2004;32:390-5.

2. Kuhnlein HV, Receveur O, Soueida R, et al. Arctic indigenous peoples experience the nutrition transition with changing dietary patterns and obesity. J Nutr 2004;134:1447-53.

3. Chateau-Degat ML, Dewailly E, Louchini R, et al. Cardiovascular burden and related risk factors among Nunavik Quebec Inuit: Insights from baseline findings in the circumpolar Inuit health in transition cohort study. Can J Cardiol 2010;26:190-6.

4. Young TK, Bjerregaard P, Dewailly E, et al. Prevalence of obesity and its metabolic correlates among the Circumpolar Inuit in three countries. Am J Public Health 2007;97:691-5.

5. Jørgensen ME, Glümer C, Bjerregaard P, et al. Obesity and central fat pattern among Greenland Inuit and a general population of Denmark (Inter99): relationship to metabolic risk factors. Int J Obes Relat Metab Disord 2003;27:1507-15.

6. Chateau-Degat ML, Dewailly E, Poirier P, et al. Comparison of diagnostic criteria of the metabolic syndrome in three ethnic groups in Canada. Metabolism 2008;57:1526-32.

7. Sagild U, Littauer J, Jespersen CS, et al. Epidemiological studies in Greenland 1962-1964. I. Diabetes mellitus in Eskimos. Acta Med Scand 1966;179:29-39.

8. Mouratoff GJ, Carroll NV, Scott EM. Diabetes mellitus in Eskimos. JAMA 1967;199:107-12.

9. Jørgensen ME, Bjerregaard P, Borch-Johnson K, et al. Diabetes and impaired glucose tolerance among the Inuit population of Greenland. Diabetes Care 2002;25:1766-71.

10. Ebbesson SO, Schraer CD, Risica PM, et al. Diabetes and impaired glucose tolerance in three Alaskan Eskimo populations: the Alaska-Siberia Project. Diabetes Care 1998;21:563-9.

11. Murphy NJ, Schraer CD, Bulkow LR, et al. Diabetes mellitus in Alaskan Yup'ik Eskimos and Athabascan Indians after $25 \mathrm{yr}$. Diabetes Care 1992;15:1390-2.

12. Aboriginal peoples survey 2006 [Table 4-7. Diagnosed with diabetes, Inuit adults aged 15 and over, Canada and Inuit regions, 2006]. Ottawa (ON): Statistics Canada; 2006. Available: www.statcan.gc.ca/pub/89-637-x/2008002/tab/tab4-7-eng.htm (accessed 2010 Nov. 1)
13. Lemieux I, Poirier P, Bergeron J, et al. Hypertriglyceridemic waist: A useful screening phenotype in preventive cardiology? Can J Cardiol 2007;23(Suppl B):23B-31B.

14. Yu D, Huang J, Hu D, et al. Is an appropriate cutoff of hypertriglyceridemic waist designated for type 2 diabetes among Chinese adults? Clin Nutr 2010;29:192-8.

15. Lemieux I, Alméras N, Mauriège P, et al. Prevalence of "hypertriglyceridemic waist" in men who participated in the Quebec Health Survey: association with atherogenic and diabetogenic metabolic risk factors. Can J Cardiol 2002;18:725-32.

16. Indigenous peoples and participatory health research. Geneva (Switzerland): World Health Organization and Centre for Indigenous Peoples' Nutrition and Environment; 2003.

17. Slein MW. Methods of enzymatic analysis. New York (NY): Academic Press; 1963. p. 1196-1201.

18. Tietz NW. Clinical guide to laboratory tests. 3rd ed. Philadelphia (PA): WB Saunders Company; 1995. p. 130-131, 842-3, 610-611.

19. Alberti KG, Zimmet P, Shaw J. Metabolic syndrome: a new world-wide definition. A consensus statement from the International Diabetes Federation. Diabet Med 2006;23:469-80.

20. Friedewald WT, Levy RI, Fredrickson DS. Estimation of the concentration of low-density lipoprotein cholesterol in plasma without use of the preparative ultracentrifuge. Clin Chem 1972; 18:499-502.

21. American Diabetes Association. Standards of medical care in diabetes - 2008. Diabetes Care 2008;31(Suppl 1):S12-54.

22. Canadian Diabetes Association Clinical Practice Guidelines Expert Committee. Canadian Diabetes Association 2008 clinical practice guidelines for the prevention and management of diabetes in Canada. Can J Diabetes 2008;32(Suppl 1):S1-201.

23. McPherson R, Frohlich J, Fodor G, et al. Canadian Cardiovascular Society. Canadian Cardiovascular Society position statement - recommendations for the diagnosis and treatment of dyslipidemia and prevention of cardiovascular disease. Can J Cardiol 2006;22:913-27.

24. Report from the National Diabetes Surveillance System: Diabetes in Canada, 2009. Ottawa (ON): Public Health Agency of Canada; 2009. Available: www.phac-aspc.gc.ca/publicat/2009 /ndssdic-snsddac-09/index-eng.php (accessed 2010 Nov. 24).

25. Young TK, Reading J, Elias B, et al. Type 2 diabetes mellitus in Canada's First Nations: status of an epidemic in progress. CMAJ 2000;163:561-6.

26. Kahn HS, Valdez R. Metabolic risks identified by the combination of enlarged waist and elevated triacylglycerol concentration. Am J Clin Nutr 2003;78:928-34.

27. Blackburn P, Lemieux I, Alméras N, et al. The hypertriglyceridemic waist phenotype versus the National Cholesterol Education Program - Adult Treatment Panel III and International Diabetes Federation clinical criteria to identify high-risk men with an altered cardiometabolic risk profile. Metabolism 2009;58:1123-30.

28. Arsenault BJ, Lemieux I, Després J-P, et al. The hypertriglyceridemic-waist phenotype and the risk of coronary artery disease: results from the EPIC-Norfolk Prospective Population Study. CMAJ 2010;182:1427-32.

Affiliations: From the Centre for Indigenous Peoples' Nutrition and Environment (CINE) and School of Dietetics and Human Nutrition (Egeland, Cao), McGill University, Ste. Anne-de-Bellevue, Que.; and the Dalla Lana School of Public Health (Young), University of Toronto, Toronto, Ont.

Contributors: Grace Egeland and Kue Young designed and conducted the study. Grace Egeland guided the statistical analyses, and Zhirong Cao conducted the statistical analyses. Grace Egeland wrote the manuscript, and all of the authors contributed important intellectual content. All of the authors approved the final version submitted for publication.

Funding: Canadian Federal Program for International Polar Year, Canadian Institutes for Health Research, Health Canada, Government of Nunavut, ArcticNet. 